\title{
Bufale spotting, part three: assessing editorials धु कु
}

Tom Jefferson ${ }^{1} \quad$ Lucia Zarra ${ }^{2}$

$J$ R Soc Med 2007; 100:267

This is the third in a series of articles on making evidence-based medicine work for you. The series is based on the book 'Attenti Alle Bufale' by Tom Jefferson (www.attentiallebufale.it).

\section{QUICK INSTRUMENT (FIGURE 1)}

- Bin any editorial quoting single studies without putting the results into context.

- Bin any editorial without a declaration of conflicts of interest.

- Beware of editorials that do not quote systematic reviews (usually identifiable from the title) and quote single studies. Possible exceptions are disciplines in which systematic reviews are few (epidemiology of disease) or are based on softer grounds (bioethics).

- Beware of editorials with catchy titles.

- Never change your clinical decision-making process on the basis of an editorial.

\section{FULL INSTRUMENT}

Alas, there is no such thing, but if you are struck by the content of the editorial, take time to research the topic. Go through the references systematically, pick one at random and check whether its content or spirit is fairly reported by the author or authors of the editorial. If not, try writing to the author and challenging his views. You will soon make up your mind as to whether you are being manipulated or not.

\section{RATIONALE}

Editorials can be very misleading. They are usually written by well-known people and can influence readers (this is the

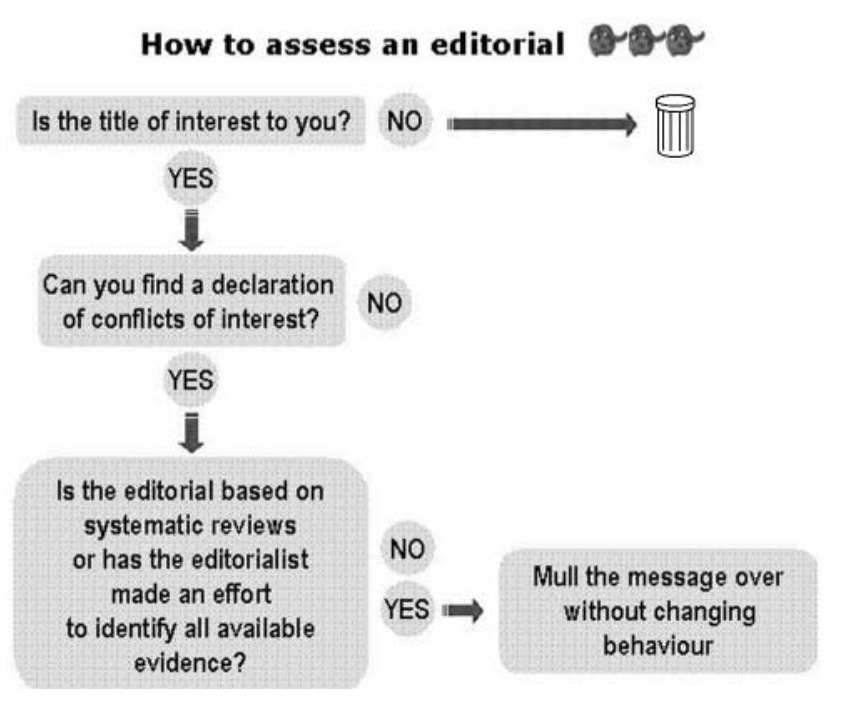

main reason for writing one). The danger lies in the fact that very often editorials are forms of synthesis of evidence, without a methods chapter. So although a powerful message is often delivered, you do not know how that message was arrived at. In addition, as the authors are active in the relevant field it is virtually impossible for them not to have some conflict of interest or other. These conflicts may not be necessarily of a financial nature. Finally, remember that the results of single studies cannot be interpreted without reference to other similar studies and by putting the evidence in context.

\section{BIBLIOGRAPHY}

1 Young C, Horton R. Putting clinical trials into context. Lancet 2005;366:107-8

\footnotetext{
${ }^{1}$ Cochrane Vaccines Field and Cochrane Acute Respiratory Infections Group, 00061 Anguillara Sabazia, Rome, Italy

${ }^{2}$ II Pensiero Scientifico Editore, Rome, Italy

Correspondence to: Tom Jefferson

E-mail: Jefferson.tom@gmail.com
} 